\title{
From Molecules to Behavior: Lessons from the Study of Rare Genetic Disorders
}

\author{
Pierre L. Roubertoux $\cdot$ Petrus J. de Vries
}

Received: 14 April 2011/Accepted: 19 April 2011/Published online: 4 May 2011

(C) Springer Science+Business Media, LLC 2011

\begin{abstract}
Rare diseases are defined as conditions with a prevalence of less than $1 / 2,000$. To date between 6,000 and 7,000 rare diseases have been identified and many of those have manifestations that include intellectual disability, developmental disorders or other behavioural phenotypes. In this special issue we bring together a range of papers where rare diseases were used as models to delineate specific aspects of learning and memory, or behaviour. In this introductory paper we summarize some of the lessons we can learn from rare diseases. Firstly, we learn that, collectively, rare diseases are not at all rare. As many as 1 in 20 individuals may be affected by a rare disease at some point in their life. Secondly, we learn that rare diseases may share common pathophysiological mechanisms. A discovery in one can therefore have direct relevance to many others. A third lesson is that the study of rare diseases can lead to an understanding of common disorders, as exemplified by the relationship between Trisomy 21 (Down syndrome) and Alzheimer's disease. A fourth lesson from rare diseases is that the 'one gene-one functional consequence' assumption is not correct. Finally, rare diseases
\end{abstract}

\section{P. L. Roubertoux}

Génétique Médicale, Génomique Fonctionnelle, Aix Marseille Université, INSERM U 910, 27 bvd Jean Moulin,

13385 Marseille cedex 5, France

\section{P. J. de Vries}

Neurodevelopmental Service (NDS), Cambridgeshire \&

Peterborough NHS Foundation Trust,

Peterborough PE3 6DB, UK

\section{P. J. de Vries $(\square)$}

Developmental Psychiatry Section, University of Cambridge,

Douglas House, 18b Trumpington Road,

Cambridge CB2 8AH, UK

e-mail: pd215@cam.ac.uk have shed new light on the strengths and weaknesses of animal models in the study of behavioural phenotypes.

Keywords Rare diseases - Behavioural phenotypes . Tuberous sclerosis · Trisomy 21 . Down syndrome . Noonan · LEOPARD · Neurofibromatosis · Williams · diGeorge $\cdot$ Rett

This issue of Behavior Genetics focuses on rare genetic diseases that affect brain and behaviour. Examples in the issue include tuberous sclerosis (historically referred to as 'Bourneville disease' in Europe), chromosome 8p inverted duplication-deletion syndrome, Trisomy 21 (Down syndrome), Noonan and LEOPARD syndromes (both associated with dysregulation of RAS/MAPK signaling), Neurofibromatosis, Williams-Beuren and DiGeorge syndromes. The common thread among these conditions is that they are all classified as 'rare diseases', and have all become heuristic models to decipher specific aspects of the relationship between gene, brain and behaviour.

The majority of papers included here were presented at the 12th International Research Symposium of the Society for the Study of Behavioral Phenotype (SSBP) held in Cambridge, UK in October 2009. Given the commonalities in the goals of the SSBP (www.ssbp.org.uk) and of the Behavior Genetics Association (BGA) (www.bga.org), we proposed to assemble a collection of papers demonstrating the interface of the two societies. We also invited submissions from researchers who did not attend the Cambridge meeting and were not members of either the SSBP or the BGA. Needless to say, all papers were rigorously peer-reviewed. In this introductory paper, we summarize some of the lessons we might learn from rare genetic disorders with regards to behavioral genetics. 


\section{Rare diseases are collectively not rare}

All the studies presented in this issue refer to rare diseases. A 'rare disease' is defined either by its estimated prevalence or by the total number per population. Interestingly, the definitions vary across the world. The USA Rare Diseases Act (2002) defines a rare disease as one that affects fewer than 200,000 USA citizens. This corresponds to a prevalence rate of approximately $1 / 1,500$. In Japan a disease is considered rare when it affects fewer than 50,000 individuals, corresponding to a lower prevalence of around 1/2,500. The European Union (EU) defines a disease as rare when its prevalence does not reach more than 1/2,000. The prevalence of many rare diseases is significantly lower than $1 / 2,000$ but there is general international consensus to define a rare disease around a median prevalence rate of $1 / 2,000$, even though this rate is not based on any actual statistical or clinical criteria. Table 1 shows the prevalence rates, as summarized by Orphanet (www.orpha.net), of the rare diseases that are referred to in this special issue.

Some diseases, such as LEOPARD syndrome, are so rare that it is not possible to calculate a prevalence ratefor these conditions Orphanet lists the total number of cases or families described in the literature to date. It is of interest that the prevalence rate of a rare disease does not necessarily correlate with how well it is known in the general or scientific community. Cystic Fibrosis and Huntington disease are, for instance, significantly better known than tuberous sclerosis or Williams syndrome.

Table 1 The prevalence of genetic disorders referred to in this issue as listed on Orphanet (www.orpha.net)

\begin{tabular}{ll}
\hline $\begin{array}{l}\text { Disorder } \\
\text { (as listed on www.orpha.net) }\end{array}$ & $\begin{array}{l}\text { Estimated prevalence } \\
(/ 100,000)\end{array}$ \\
\hline Angelman syndrome & 6.5 \\
Coffin-Lowry syndrome & 0.55 \\
Cornelia de Lange syndrome & 1.9 \\
Cystic Fibrosis & 12 \\
Down syndrome (Trisomy 21) & 50 \\
Fragile-X syndrome & 14.25 \\
Huntington disease & 5.9 \\
Lesch-Nyhan syndrome & 0.38 \\
Neurofibromatosis type 1 & 25 \\
Noonan syndrome & 50 \\
Phenylketonuria & 4 \\
Prader-Willi syndrome & 10.7 \\
Rett syndrome & 4.15 \\
Smith-Magenis syndrome & 4 \\
Tuberous sclerosis & 8.8 \\
Williams syndrome & 13.3
\end{tabular}

Prevalence rates were calculated based on European statistics
Even though these conditions are individually rare, the total number of rare diseases is remarkably high. INSERM and NIH epidemiological studies converge on an estimation of 7,000 rare diseases, suggesting that as many as 1 in 20 patients (5\%) around the world will be affected by a rare disease. It is estimated that there are fifteen million patients with one of the 7,000 known rare diseases living in the USA alone.

Apart from the obvious public health burden of rare diseases collectively, investigation of the psychiatric, psychological and neuronal aspects of rare diseases has clearly become important. We demonstrate here how brain and behavioural studies of these diseases may generate heuristic neurogenetic models to understand behaviour not only of relevance to the so-called rare disease themselves, but also to a much larger collective population.

\section{Rare diseases may share common pathophysiological mechanisms}

On first inspection, research into the mechanisms of an ever-increasing number of rare diseases might appear as fruitless as the Greek legend of Sisyphus pushing his boulder up a mountain for eternity. However, many rare diseases share pathophysiological mechanisms and advances in the knowledge or treatment of one disease can contribute to knowledge and treatment of other diseases. This provides a powerful challenge to potential initial pessimism. In this issue, we examine several rare diseases that share pathophysiological mechanisms and we highlight two examples of shared mechanisms in this introductory paper. The first is the set of diseases that share dysregulation of an important signaling pathway, the PI3KmTOR pathway. The second example is of diseases that share dysregulation of micro-RNAs (mi-RNAs). For a glossary of terms used in this issue, see Table 2.

Tuberous sclerosis complex (TSC) illustrates the first example. Since the initial identification of the TSCl and TSC2 genes, mutations in which are responsible for the disease, and the realization that hamartin (TSC1) and tuberin (TSC2) act as an intracellular complex in the PI3KmTOR (mammalian Target of Rapamycin) signaling pathway, a number of other rare diseases have been shown to lead to mTOR dysregulation. These include fragile X syndrome, neurofibromatosis type 1 and the disorders associated with MAPK dysregulation, such as Noonan and LEOPARD syndromes. For instance, there is now evidence that lack of FMRP leads to mTOR overactivation (Sharma et al. 2010). The NF1 protein, neurofibromin, functions as a Ras-GTPase activating protein via PI3K-AKTTSC2 and regulates mTOR. In NF1 deficient cells mTOR is constitutively activated. On TSC2 there are direct 
Table 2 Glossary of terms used in this issue

\begin{tabular}{|c|c|}
\hline AKT & $\begin{array}{l}\text { Protein kinase B; a serine/threonine kinase signaling between PI3K and TSC2; involved in insulin } \\
\text { signalling, cell proliferation, apoptosis }\end{array}$ \\
\hline APP & Amyloid beta (A4) precursor protein \\
\hline APRT & $\begin{array}{l}\text { Adenine phosphoribosyltransferase; functionally related to HPRT both of which function } \\
\text { in the purine salvage pathway }\end{array}$ \\
\hline ASD & Autism spectrum disorder \\
\hline BGA & Behavior Genetics Association \\
\hline DGCR8 & $\begin{array}{l}\text { diGeorge critical region } 8 \text { protein encoded by the } D G C R 8 \text { gene in humans; one of the } \sim 40 \text { genes involved } \\
\text { in } 22 \text { q11 deletion syndrome (diGeorge syndrome) }\end{array}$ \\
\hline DSCAM & Down syndrome cell adhesion molecule (human protein); Dscam refers to its homologue in Drosophila \\
\hline ERK1/2 & Extracellular signal-regulated kinases; also referred to as MAPK $3 / 2$ \\
\hline FMRP & Fragile $\mathrm{X}$ mental retardation protein; encoded by $F M R 1$ (fragile $\mathrm{X}$ mental retardation 1) gene \\
\hline GTPase & Large group of hydrolase enzymes that bind and hydrolyze guanosine triphosphate (GTP) \\
\hline HPRT & $\begin{array}{l}\text { Hypoxanthine-guanine phosphoribosyltransferase; human enzyme that plays an important role } \\
\text { in the purine salvage pathway. Mutation in the HPRT1 gene leads to Lesch-Nyhan syndrome }\end{array}$ \\
\hline HSA & Followed by a number, $\mathrm{X}$ or Y indicates a Homo Sapiens chromosome, e.g. HSA21 or HSAX \\
\hline MAPK & $\begin{array}{l}\text { Mitogen-activated protein (MAP) kinases; serine/threonine-specific kinases that respond to extracellular stimuli } \\
\text { (such as mitogens, stress etc.) and regulate various intracellular events (such as gene expression, } \\
\text { differentiation, proliferation) }\end{array}$ \\
\hline$M E C P 2$ & Methyl CpG binding protein 2 gene; located at Xq28; mutations in $M E C P 2$ are the cause of Rett syndrome \\
\hline MK2 & Mitogen-activated protein kinase-activated protein kinase 2 \\
\hline mRNA & Messenger ribonucleic acid (RNA) \\
\hline mi-RNA & $\begin{array}{l}\text { micro-RNA; short RNA molecules of about } 22 \text { nucleotides in length; post-transcriptional regulators } \\
\text { that bind to complementary sequences on messenger RNA transcripts }\end{array}$ \\
\hline mTOR & $\begin{array}{l}\text { Mammalian Target of Rapamycin; intracellular serine/threonine protein kinase that regulates cell growth, } \\
\text { proliferation, apoptosis and protein synthesis }\end{array}$ \\
\hline NF1 & Neurofibromatosis type 1 \\
\hline PI3K & $\begin{array}{l}\text { Phosphatidylinositol 3-kinases; PI3Ks interact with the insulin receptor substrate to regulate glucose uptake; also } \\
\text { involved in various other intracellular processes such as cell growth, proliferation and cell survival }\end{array}$ \\
\hline Ras & Small GTPase proteins involved in intracellular signalling \\
\hline RISC & $\begin{array}{l}\text { RNA-induced Silencing Complex; multiprotein complex that incorporates a strand of si-RNA or mi-RNA as a } \\
\text { template to recognize complementary mRNA }\end{array}$ \\
\hline si-RNA & $\begin{array}{l}\text { Small interfering RNA or silencing RNA; class of double-stranded RNA with a key role } \\
\text { in RNA interference (RNAi) where it interferes with expression of a specific gene }\end{array}$ \\
\hline SSBP & Society for the Study of Behavioural Phenotypes \\
\hline TSC & $\begin{array}{l}\text { Tuberous Sclerosis Complex; multisystem genetic disorder associated with mutation } \\
\text { in } T S C 1 \text { (9q34) or TSC2 (16p13.3) }\end{array}$ \\
\hline TSC1 & Hamartin, protein product of the TSC1 gene \\
\hline TSC2 & Tuberin, protein product of the $T S C 2$ gene \\
\hline
\end{tabular}

phosphorylation sites for p38 MAPK-activated protein kinase (MK2) and for extracelluar signal regulated kinase 1 and 2 (ERK1/2), the proteins implicated in Noonan and LEOPARD syndromes (Kobayashi et al. 2010; Krenz et al. 2008). Given that tuberous sclerosis is an mTOR overactivation syndrome, a number of clinical trials are underway using mTOR inhibitors, such as rapamycin and everolimus, as molecularly targeted treatments for many of the physical manifestations of the disorder. Early-phase clinical trials also suggest that specific aspects of neurocognition, such as recall memory, may be improved through mTOR inhibitors in patients with tuberous sclerosis. Given the shared pathophysiological mechanisms between tuberous sclerosis and these other rare diseases, mTOR inhibitors may therefore also have direct potential in the treatment of other rare diseases (de Vries 2010).

Dysregulation of micro-RNAs (mi-RNA) provides a second illustration of shared pathophysiological mechanisms. Mi-RNAs belong to the family of small RNAs that also includes esi-RNAs and pi-RNAs (Lee et al. 1993). They are non-coding, single stranded and about 22 nucleotides long. The ENCODE Project Consortium (2007), Amaral et al. (2009) and Kim et al. (2009) summarized the enzymatic and cellular processes by which mi-RNAs 
regulate the translation of target mRNA in a sequencespecific manner. Briefly, mi-RNAs are post-transcriptional regulators (Roubertoux et al. 2010). They bind to complementary sequences on mRNA transcripts, resulting in gene silencing or in translational repression. About one thousand mi-RNAs, targeting $60 \%$ of the genes, are encoded in mammalian genomes. Disturbances in mi-RNA function contribute to abnormalities of brain development and subsequent impairment of cognitive functions in a number of rare neurodevelopmental disorders. This is illustrated by the fact that transgenic mice conditionally expressing mi-R132 in forebrain neurons present dendritic spine abnormalities and learning impairment (Hansen et al. 2010). Several mi-RNAs are involved in Fragile X syndrome, Rett syndrome, DiGeorge syndrome and Trisomy 21. The contributing mi-RNAs are not the same in every brain disease but all four diseases present an impairment of post-transcriptional processes.

Fragile $\mathrm{X}$ syndrome is the most common cause of intellectual disability caused by mutations affecting a single gene. The gene involved is FMR-1 (Fragile X Mental retardation-1), located on the $\mathrm{X}$ chromosome at Xq27.3. The syndrome is caused by an expansion of CGG (cytosine-guanine-guanine) repeats in the $5^{\prime}$ UTR of the FMR-1 gene. The normal size of the CGG repeats ranges from 5 to 54. When there are more than 200 repeats, the FMRl gene does not produce the FMR1 protein. Qurashi and Jin (2010) reported several lines of evidence for interactions between mi-RNA biogenesis and FMR1. From a biochemical perspective, Drosophila FMR1 (dFMR1) interacts with RISC proteins including three involved in mi-RNA biogenesis (dAgo1, dAgo2 and Dicer). The interaction of $d F m r l$ with $d$ Agol has been shown by studies both of overexpression and of loss-of-function of $d F m r l$. Qurashi and Jin (2010) suggested a model for FMR1 function in which mi-RNAs play a crucial role. According to the model, FMR1 facilitates the interaction between mi-RNAs and their target mRNA sequences. This process ensures proper targeting of guide mi-RNA-RISC within the 3 '-UTRs and translational suppression. The lack of FMR1 in fragile $\mathrm{X}$ syndrome thus dysregulates the suppression of target mRNAs.

Rett syndrome is defined by a complex phenotype combining brain, motor and cognitive dysfunction. The disease is associated with a mutation in the $M E C P 2$ gene encoding methyl-CpG-binding protein 2 (Bienvenu et al. 2000). Wu et al. (2010) investigated the role of mi-RNA on brain functions using a mouse model of Rett-syndrome. Mecp2 directly represses the transcription of several miRNAs, including a number that target the $3^{\prime}$ UTR of $B d n f$ mRNA. Furthermore, Mecp2 directly regulates a large cluster of mi-RNAs within the Dlkl-Gtl2 imprinting domain. Kernohan et al. (2010) pointed out that the methylation region close to the Gtl2 promoter is associated with X-linked $\alpha$ thalassemia/mental retardation syndrome (168 patients reported in the European Community), suggesting a role for Mecp2 in the transcriptional control of this region.

DiGeorge syndrome results from hemizygous deletion on chromosome 22q11.2. The region carries Drosha homologous (DGCR8) that are crucial in mi-RNA biogenesis. DGCR8 itself has a direct effect on brain function and cognition, as shown by the observation that insertional inactivation of the gene induces learning impairment in mice carrying one null DGCR8 allele (Stark et al. 2008).

Trisomy 21 is due to a triplication of all or part of human chromosome 21 (HSA21). The disease is the most common cause of intellectual disability. HSA21 encompasses five mi-RNA genes: MiR-99a, Let-7c, MiR-125b-2, MiR-155, and MiR-802 (Kuhn et al. 2008). Another miRNA (MiR-139) was recently identified (URL: http:// www.informatics.jax.org, 2011). There is direct evidence that MiR-99a, Let-7c, MiR-125b-2 and MiR-802 are overexpressed in fetal brain and heart of individuals with Trisomy 21 (Kuhn et al. 2008). It is well-known that the brain is affected in all individuals with Trisomy 21 and that $56 \%$ of patients have heart defects (Roubertoux and Carlier 2010). The MiR-155 and MiR-139 genes are close to APP, on the telomeric side, in a chromosomal region that is not involved in trisomic brain and cognitive difficulties (Sérégaza et al. 2006).

These examples show that the post-transcriptional activity of mi-RNAs could be one of the common mechanisms involved in the development of several rare diseases. In the case of X-linked thalassemia/mental retardation syndrome and Rett syndrome, the overlap is even more striking, with both syndromes apparently affecting a shared set of target genes.

\section{The study of rare diseases can lead to an understanding of common diseases}

The exploration of rare diseases paves the way for understanding the causes and mechanisms of more common diseases, clearly illustrated by the relationship between Trisomy 21 and Alzheimer's disease. Alzheimer's disease is one of the key international public health challenges, predicted to affect 1 in 85 people by 2050 (Brookmeyer et al. 2007). The level of abnormal cleavage products of Amyloid Precursor Protein (APP) is between 3 and 5\% in Alzheimer's disease. The study of Trisomy 21 has played a crucial role in identification of $A P P$ as a cause of Alzheimer disease. Hardy and Allsop (1991) were the first to hypothesize that amyloid deposits could be the central event in Alzheimer's disease. The intellectual decline that arises in individuals with Trisomy 21 when they are in their 
forties, the presence of amyloid deposits in the brain (cortex and hippocampus), and the location of $A P P$ on HSA 21 confirmed the contribution of $A P P$ to inherited forms of Alzheimer disease.

Another example of how studies of rare diseases may pave the way for understanding more common ones comes from the study of Waltereit and colleagues in this issue (Waltereit et al. 2011). They used a naturally occurring TSC2 rat, the Eker rat, to examine the relationship between seizures and autism. Autism spectrum disorders (ASD) are now recognized in almost $1 \%$ of the population, making it remarkably common. There is clear evidence in the literature that seizures and epilepsy correlate with autism spectrum disorders, but very few if any experimental studies have been performed to determine whether there may be a causal relationship between epilepsy and ASD. Waltereit showed that, although wild-type rats had no social deficit behaviours, the $T s c 2^{+/-}$rats showed specific social deficits. After the induction of status epilepticus both wild-type and $T s c 2^{+/-}$rats showed some social deficits, but the social deficits were different from those present in the untreated $T s c 2^{+/-}$rats. If these findings are borne out in other studies, results may provide support for an additive causal model of autism where a rare disease mutation is sufficient to lead to some ASD features and the epilepsy contributes additional (but different) social deficits to cross the diagnostic threshold for ASD, thus showing how a rare disease can shed light on the mechanisms of common disorders.

\section{Rare diseases challenge the 'one gene-one functional consequence' assumption}

The study of the genetic origin of inter-individual variability is of significant interest to behavioural geneticists. Initial findings in behavioural genetics generated a 'one gene-one protein' assumption. We know now that this assumption is an oversimplification. Rare diseases have helped to clarify that individual gene products may have multiple different functions (see for instance Serfontein et al. 2011, this issue). Thus different mutations in a single gene may have a range of functional consequences, both at a biochemical and phenotypic level. Tierney et al. (2011) clearly illustrate the variability of phenotypic expression in a group of normally-intelligent adults with tuberous sclerosis in spite of the fact that the majority had a mutation in the same gene.

The concept of the multifunctional gene proposes that different alleles of a given gene might generate several different forms of a protein and therefore have several different phenotypes (Roubertoux 2004; Roubertoux and Carlier 2007). The human neuroligin 4 gene associated with different brain disorders provides a demonstration of the multifunctionality of the gene. The neuroligin 4 gene is located on HSAX. A frameshift mutation in codon 396 (GAC, encoding aspartate, transformed in TGA, a stop codon) results in a truncated protein associated with autism spectrum disorders (Jamain et al. 2003) whereas a deletion of two nucleotides in codon 418 (GAG, glutamate, turning it into GAC, aspartate) leads to modification of codons 418-429 and of the corresponding 11 amino acids, resulting in a stop codon (TAA) at codon 429 (instead of GAT, aspartate), and a truncated protein associated with intellectual disability (Laumonnier et al. 2004).

Alternative splicing is a powerful contributor to gene multifunction (Roubertoux 2004; Ule et al. 2006). After transcription, the intronic regions are eliminated whereas the exonic regions alone are left in the transcript. The step is referred to as "regular" splicing. Bypassing of splice sites, either physiologically or through mutation can occur at the boundaries of exons and introns, resulting in the elimination of exons. The process generates new proteins and subsequently new phenotypes. The Drosophila Down syndrome cell adhesion molecule (Dscam) gene, which encodes an axon guidance receptor, can express 38,016 different messenger RNAs, thus 38,016 possible proteins and 38,016 different functions (Schmucker et al. 2000). About $95 \%$ of genes exhibit between 3 and 5 "alternative" splicings. The occurrence of alternative splicing varies in tissue types and may, for instance, vary between frontal cortex and hippocampus. Alternative splicing therefore challenges the notion of genetic "causality" and genetic "determinism" given that the gene product is not predicted from the DNA template only. Thus although a typical phenotype might be expected from an inherited gene, a splicing alteration might generate a pathological phenotype.

\section{Rare diseases shed new light on the strengths and weaknesses of animal models in the study of behavioural phenotypes}

As well as offering the possibility of confirming the role of specific genes in causing diseases, appropriate animal models have led to advances in understanding the pathophysiology and development of treatment strategies for these diseases. Drosophila (fruitfly), Caenorhabditis elegans (nematode worm) and Danio rerio (zebrafish) are often used as molecular or cellular models, whereas rodents are preferred when the brain and behavioural aspects constitute key aspects of the phenotype. However, rare diseases point out a number of factors to consider when using animal models to study human disease. 
In this issue, Serfontein and colleagues (2011) used a bioinformatic approach to study the presence of structural and functional elements of TSC1 and TSC2 across a number of animal models commonly used to study physical or behavioural phenotypes of human disorders. They reported very high similarity to the human protein sequences for rat and mouse, but not for zebrafish, fruitfly or yeast. Their results therefore illustrate the importance of caution when interpreting results from some of these animal models, especially as they relate to the function of specific residues in the proteins concerned.

Animal models should also be used carefully when studying particular behavioural phenotypes, particularly when translating cognitive processes between humans and animal models. 'Intellectual disability' in a human (defined as performance below $2 \mathrm{SD}$ of the mean on formal IQ testing accompanied by impaired adaptive behaviour) does not have a true equivalent in animal models. Poor performance on the Morris water maze or in the radial maze is not sufficient as a proxy for intellectual disability, given that poor performance on these two tasks may result from impairment in different cognitive processes. Cognitive sciences have identified different kinds of memory corresponding to different brain substrates (Milner et al. 1998). The comparisons between Trisomy 21 and Williams-Beuren syndrome in this issue illustrate the importance of dissecting specific aspects of memory impairment (see the two papers by Menghini et al. 2011a, b). A further difficulty results from the fact that the same phenotype may be associated with different diseases. Tordjman et al. (2007) discussed the well-known cerebellar hypoplasia that was considered as a sign of autism. However, cerebellar hypoplasia is seen in several disease including Trisomy 21 , Williams-Beuren and various forms of muscular dystrophy.

Lesch-Nyhan syndrome provides a further lesson about genetic differences between mice and men. Homologous hypoxanthine phospho-ribosyltransferase genes (HPRT in man and Hprt in mice) regulate the metabolism of purines. Deletion of the Hprt gene in mice, however, does not induce a phenotypic disorder, whereas a human HPRT mutation would cause Lesch-Nyhan syndrome. The boys carrying one of the numerous mutations of the HPRT gene present a lack of HPRT, inducing abnormal purine metabolism (over-production and over-excretion of purines). The absence of a phenotype associated with the deletion of the homologous Hprt gene in the mouse is explained by different purine metabolism in the two species. Wild-type mice do not salvage circulated hypoxanthine. Wu and Melton (1993) hypothesized that mice are protected against HPRT loss and that purine metabolism is less HPRT dependent in the mouse than in humans. The HPRT/APRT quotient was shown to be lower in mice than in humans and, as a result, the authors suspected the second enzyme (adenine phosphoribosyl-transferase-APRT) to be involved in the mouse purine salvage pathway. Administration of an inhibitor of APRT (9-ethyladenine) to mice lacking HPRT led to a self-injurious behavior phenotype that characterizes Lesch-Nyhan syndrome in humans.

A further lesson from rare diseases is that animal models are not always necessary to develop a targeted treatment. In some cases, discovery of the cause and effective treatment of a rare metabolic disorder can be done without an animal model. Phenylketonuria, caused by mutations of the phenylalanine hydroxylase gene (12q23.2-q24.1), results in severe cognitive impairment and behavioral disorders. A special diet to prevent the metabolic disorder from birth reduces the cognitive and behavioural symptoms and, inter alia, improves the actual cognitive processes (Carlier and Ayoun 2007; Williams et al. 2008). Of course it is also true that several successful treatment strategies identified in mouse models of rare genetic diseases have led to clinical trials (Salehi et al. 2009; Roux et al. 2007; Varela et al. 2008). It is striking how many rare diseases have become powerful models of translational medicine and translational neuroscience, exactly because these diseases have allowed us to progress from an understanding of their underlying mechanisms to the brain and behavioural phenotypes.

\section{Conclusion}

Rare genetic disorders have clearly come of age, and are increasingly recognized and utilized as heuristic models in the study of behaviour. Apart from international learned organizations such as the Behaviour Genetic Association (BGA) and the Society for the Study of Behavioural Phenotypes (SSBP) whose primary aims are to promote awareness and high-quality research in behavioural genetics and behavioural phenotypes of rare genetic diseases, there are also national and international bodies including Orphanet (Europe), the NIH Office of Rare Diseases Research (USA) and Rare Disease UK, that are championing the clinical importance and scientific value of rare diseases.

Acknowledgments The 12th International Research Symposium of the SSBP was funded by the TS Alliance and the ERS Charitable Foundation. The Foundation Jerome Lejeune is acknowledged for grant support to Pierre Roubertoux. We would like to thank Prof Christopher Howe (Department of Biochemistry, University of Cambridge) for extremely helpful comments on an earlier draft of this introductory paper. Thanks are also due to Prof Nicolas Lévy (Génétique Médicale, Génomique Fonctionnelle, Marseille and Chair of the GIS "maladies rares, INSERM") for long discussions on rare diseases. 


\section{References}

Amaral FC, Torres N, Saggioro F, Neder L, Machado HR, Silva WA Jr, Moreira AC, Castro M (2009) MicroRNAs differentially expressed in ACTH-secreting pituitary tumors. J Clin Endocrinol Metab 94:320-323

Bienvenu T, Carrié A, de Roux N, Vinet MC, Jonveaux P, Couvert P, Villard L, Arzimanoglou A, Beldjord C, Fontes M, Tardieu M, Chelly J (2000) MECP2 mutations account for most cases of typical forms of Rett syndrome. Hum Mol Genet 22:1377-1384

Brookmeyer R, Johnson E, Ziegler-Graham K, Arrighi H (2007) Forecasting the global burden of Alzheimer's disease. Alzheimers Dement 3:186-191

Carlier M, Ayoun C (2007) Déficiences intellectuelles et intégration sociale. Wavre, Belgique, Mardaga

de Vries PJ (2010) Targeted treatments for cognitive and neurodevelopmental disorders in tuberous sclerosis complex. Neurotherapeutics 7:275-282

ENCODE Project Consortium (2007) Identification and analysis of functional elements in $1 \%$ of the human genome by the ENCODE pilot project. Nature 447:799-816

Hansen KF, Sakamoto K, Wayman GA, Impey S, Obrietan K (2010) Transgenic miR132 alters neuronal spine density and impairs novel object recognition memory. PLoS ONE 5:e15497

Hardy J, Allsop D (1991) Amyloid deposition as the central event in the aetiology of Alzheimer's disease. Trends Pharmacol Sci 12:383-388

Jamain S, Quach H, Betancur C, Råstam M, Colineaux C, Gillberg IC, Soderstrom H, Giros B, Leboyer M, Gillberg C, Bourgeron T, Paris Autism Research International Sibpair Study (2003) Mutations of the X-linked genes encoding neuroligins NLGN3 and NLGN4 are associated with autism. Nat Genet 34:27-29

Kernohan KD, Jiang Y, Tremblay DC, Bonvissuto AC, Eubanks JH, Mann MR, Bérubé NG (2010) ATRX partners with cohesin and $\mathrm{MeCP} 2$ and contributes to developmental silencing of imprinted genes in the brain. Dev Cell 18:191-202

Kim VN, Han J, Siomi MC (2009) Biogenesis of small RNAs in animals. Nat Rev Mol Cell Biol 10:126-139

Kobayashi T, Aoki Y, Niihori T, Cavé H, Verloes A, Okamoto N, Kawame H, Fujiwara I, Takada F, Ohata T, Sakazume S, Ando T, Nakagawa N, Lapunzina P, Meneses AG, Gillessen-Kaesbach G, Wieczorek D, Kurosawa K, Mizuno S, Ohashi H, David A, Philip N, Guliyeva A, Narumi Y, Kure S, Tsuchiya S, Matsubara Y (2010) Molecular and clinical analysis of RAF1 in Noonan syndrome and related disorders: dephosphorylation of serine 259 as the essential mechanism for mutant activation. Hum Mutat 31:284-294

Krenz M, Gulick J, Osinska HE, Colbert MC, Molkentin JD, Robbins J (2008) Role of ERK1/2 signaling in congenital valve malformations in Noonan syndrome. Proc Natl Acad Sci USA 105:18930-18935

Kuhn DE, Nuovo GJ, Martin MM, Malana GE, Pleister AP, Jiang J, Schmittgen TD, Terry AV Jr, Gardiner K, Head E, Feldman DS, Elton TS (2008) Human chromosome 21-derived miRNAs are overexpressed in down syndrome brains and hearts. Biochem Biophys Res Commun 370:473-477

Laumonnier F, Bonnet-Brilhault F, Gomot M, Blanc R, David A, Moizard MP, Raynaud M, Ronce N, Lemonnier E, Calvas P, Laudier B, Chelly J, Fryns JP, Ropers HH, Hamel BC, Andres C, Barthélémy C, Moraine C, Briault S (2004) X-linked mental retardation and autism are associated with a mutation in the NLGN4 gene, a member of the neuroligin family. Am J Hum Genet 74:552-557

Lee RC, Feinbaum RL, Ambros V (1993) The C. elegans heterochronic gene lin- 4 encodes small RNAs with antisense complementarity to lin-14. Cell 75:843-854
Menghini D, Costanzo F, Vicari S (2011a) Relationship between brain and cognitive processes in Down syndrome. Behav Genet. doi:10.1007/s10519-011-9448-3

Menghini D, Di Paola M, Federico F, Vicari S, Petrosini L (2011b) Relationship between brain abnormalities and cognitive profile in Williams syndrome. Behav Genet. doi:10.1007/s10519-0109419-0

Milner B, Squire LR, Kandel ER (1998) Cognitive neuroscience and the study of memory. Neuron 20:445-468

Qurashi A, Jin P (2010) Small RNA-mediated gene regulation in neurodevelopmental disorders. Curr Psychiatry Rep 12:154-161

Rare Diseases Act of 2002 (2002) Public Law 107-280, 107th congress

Roubertoux PL (2004) Existe-t-il des Gènes du Comportement? Paris. Odile Jacob, France

Roubertoux PL, Carlier M (2007) From DNA to mind. The decline of causality as a general rule for living matter. EMBO 8:S7-11

Roubertoux PL, Carlier M (2010) Mouse models of cognitive disabilities in trisomy 21 (Down syndrome). Am J Med Genet C Semin Med Genet 154C:400-416

Roubertoux PL, Jamon M, Carlier M (2010) Brain development, genes, epigenetic events and maternal environments. In: Blumberg M, Freeman JH, Robinson SR (eds) Oxford handbook of developmental neuroscience. Oxford Library of Neuroscience. Oxford University Press, Oxford, pp 51-75

Roux JC, Dura E, Moncla A, Mancini J, Villard L (2007) Treatment with desipramine improves breathing and survival in a mouse model for Rett syndrome. Eur J Neurosci 25:1915-1922

Salehi A, Faizi M, Colas D, Valletta J, Laguna J, Takimoto-Kimura R, Kleschevnikov A, Wagner SL, Aisen P, Shamloo M, Mobley WC (2009) Restoration of norepinephrine-modulated contextual memory in a mouse model of Down syndrome. Sci Transl Med 1:7ra17

Schmucker D, Clemens JC, Shu H, Worby CA, Xiao J, Muda M, Dixon JE, Zipursky SL (2000) Drosophila Dscam is an axon guidance receptor exhibiting extraordinary molecular diversity. Cell 101:671-684

Sérégaza Z, Roubertoux PL, Jamon M, Soumireu-Mourat B (2006) Mouse models of cognitive disorders in trisomy 21: a review. Behav Genet 36:387-404

Serfontein J, Nisbet RER, Howe CJ, de Vries PJ (2011) Conservation of structural and functional elements of TSC1 and TSC2: a bioinformatic comparison across animal models. Behav Genet. doi:10.1007/s10519-010-9440-3

Sharma A, Hoeffer CA, Takayasu Y, Miyawaki T, McBride SM, Klann E, Zukin RS (2010) Dysregulation of mTOR signaling in fragile X syndrome. J Neurosci 30:694-702

Stark KL, Xu B, Bagchi A, Lai WS, Liu H, Hsu R, Wan X, Pavlidis P, Mills AA, Karayiorgou M, Gogos JA (2008) Altered brain microRNA biogenesis contributes to phenotypic deficits in a 22q11-deletion mouse model. Nat Genet 40:751-760

Tierney KM, McCartney DL, Serfontein JR, de Vries PJ (2011) Neuropsychological attention skills and related behaviours in adults with tuberous sclerosis complex. Behav Genet. doi:10.1007/s10519-010-9423-4

Tordjman S, Drapier D, Bonnot O, Graignic R, Fortes S, Cohen D, Millet B, Laurent C, Roubertoux PL (2007) Animal models relevant to schizophrenia and autism: validity and limitations. Behav Genet 37:61-78

Ule J, Stefani G, Mele A, Ruggiu M, Wang X, Taneri B, Gaasterland T, Blencowe BJ, Darnell RB (2006) An RNA map predicting Nova-dependent splicing regulation. Nature 444:580-586

Varela I, Pereira S, Ugalde AP, Navarro CL, Suárez MF, Cau P, Cadiñanos J, Osorio FG, Foray N, Cobo J, de Carlos F, Lévy N, Freije JM, López-Otín C (2008) Combined treatment with statins 
and aminobisphosphonates extends longevity in a mouse model of human premature aging. Nat Med 14:767-772

Waltereit R, Japs B, Schneider M, de Vries PJ, Bartsch D (2011) Epilepsy and Tsc2 haploinsufficiency lead to autistic-like social deficit behaviours in rats. Behav Genet. doi:10.1007/s10519010-9399-0

Williams RA, Mamotte CD, Burnett JR (2008) Phenylketonuria: an inborn error of phenylalanine metabolism. Clin Biochem Rev 29:31-41
Wu CL, Melton DW (1993) Production of a model for Lesch-Nyhan syndrome in hypoxanthine phophoribosyltransfer-ase-deficient mice. Nat Genet 3:235-240

Wu H, Tao J, Chen PJ, Shahab A, Ge W, Hart RP, Ruan X, Ruan Y, Sun YE (2010) Genome-wide analysis reveals methyl-CpGbinding protein 2-dependent regulation of microRNAs in a mouse model of Rett syndrome. Proc Natl Acad Sci USA 107:18161-18166 